\title{
Monseñor Romero, un enviado de Dios para salvar a su pueblo
}

\author{
Ignacio Ellacuría \\ Centro de Reflexión Teológica, \\ San Salvador, El Salvador.
}

Hace ocho meses, un 24 de marzo, caía ante el altar Monseflor Romero. Bastó con un tiro al corazón para acabar con su vida mortal. Estaba amenazado hacía meses y nunca buscó la menor protección. El 'mismo manejaba su carro y vivía en un indefenso apartamento adosado a la Iglesia donde fue asesinado. Lo mataron los mismos que matan al pueblo, los mismos que en este afio de su martirio llevan exterminadas cerca de diez mil personas, la mayor parte de ellas jóvenes campesinos, obreros y estudiantes, pero también ancianos, mujeres y niños que son sacados de sus ranchos y aparecen poco después torturados, destrozados, muchas veces irreconocibles. No importa determinar quién fue el que disparó. Fue el mal, fue el pecado, fue el anti-Cristo, pero un mal, un pecado y un anti-Cristo históricos, que se han encamado en unas estructuras injustas y en unos hombres que han elegido el papel de Caín. Sólo tuvo tres años de vida pública como arzobispo de San Salvador. Fueron suficientes para sembrar la palabra de Dios, para hacer presente en su pueblo la figura de Jesús; fueron demasiados para los que no pueden tolerar la luz de la verdad y el fuego del amor.

¿Cuál fue el misterio y el testimonio de este hombre que en tres años pasó del anonimato y de la inoperancia a la universalidad pública y al máximo de eficacia social, sin dejar nunca de ser un cristiano, un pastor, un profeta y un sacerdote?

\section{La fuerza histórica del evangelio}

La teología de la Liberación se ha esforzado en demostrar que el evangelio es, a la par que una fuerza salvííca, una fuerza histórica. Y lo es más auténticamente, cuando es más auténticamente cristiana Ve como una exigencia in- 
Urínseca del cristianismo el llegar a ser una fuerza histórica, pero no por el rodeo de la cristiandad o por formas semejantes de historización, sino en cuanto puro evangelio encamado en la realidad historica de los hombres.

Monseffor Romero es un egregio ejemplo de esta fuerza histórica del evangelio. Ninguna duda cabe y nadie se aureve a negarlo, que se convirtió cn los tres últimos años de su vida en una figura poderosísima dentro del proceso social salvadoreño. Pero lo importante es subrayar que consiguió esto no sólo sin salirse de sus funciones episcopales, sino por realizarlas plenamente. Es claro que el mero hecho de ser obispo, a pesar del peso social que la figura episcopal conserva todavía en El Salvador, no explica su tremendo impacto social, pues los demás obispos salvadorefios no la tienen. Lo que lo explica es su modo de ser obispo, de ser crisliano, de ser sacerdote.

Todavia esto resulta más claro si atendemos a la relativa inoperancia de sus anteriores aflos de sacerdote y de episcopado. ¿No era antes y después de su nombramiento como arzobispo de San Salvador la misma persona con las mismas cualidades y la misma preparacion? ¿No eran semejantes las circunstancias históricas de opresión y represión? ¿Qué, entonces, ocurrió de nuevo en esos tres últimos años de su ministerio?

Lo nuevo fue que alcanzó a historizar debidamente la fuerza del evangelio. Su mérito y su grandeza, la causa última de su influjo sin precedentes no estuvieron en que fuera un líder político, ni un intelectual, ni un gran orador. La causa última es que se puso a anunciar y realizar el evangelio en loda su plenitud y con plena encarnación. En su etapa anterior, Monsefior Romero fue un sacerdote y un obispo de buena voluntad, un hombre piadoso de oración, un celoso pastor. Incluso estaba considerado como espiritualista y, consecuentemente, reacio a inmiscuirse directamente en asuntos temporales. Trataba con los ricos y no desdeñaba a los pobres, Pero con todo ello apenas representaba algo en la Iglesia de El Salvador y más bien cra considerado como oponente al nuevo movimiento eclesial despertado en Medellín. Interesado, sobre todo, por la ortodoxia, desconfiaba de las nuevas formulaciones de la teologia de la liberación e incluso tachaba de contagio manxista a quienes denunciaban la injusticia estructural del país.

Su palabra pastoral decía algo a unas pequeñas élites, trabajadas por el Opus Dei, o a grupos clásicos del movimiento familiar cristiano. Pero el dolor y la miseria del pueblo apenas le decía algo a él y él no significaba apenas nada para el pueblo. Aquí va a estar la clave, como luego veremos, pero ya desde ahora debe quedar claro que, antes de su conversión, no supo historizar adecuadamente lo más verdadero y vital del Evangelio.

\section{La conversírin de Monseñor Romero}

No fue su nombramicnto como arzobispo de San Salvador lo que hizo 
cambiar a Monsefíor Romero. Más bien fue elegido para que la incipiente opción preferencial por los pobres de la arquidiocesis fuera contenida y sometida a cauces más tradicionales. Aquella incipiente opción ya habia obligado a diversos sectores de la arquidiocesis a nuevas orientaciones en la pastoral y a los primeros enfrentamientos proféticos con las autoridades del pars y con la clase dominante. Para evitar esto se nombro a Monseftor Romero frente al candidato de la parte más comprometida de la arquidiócesis que era Monseñor Rivera y Damas.

$Y$, sin embargo, Monseflor Romero se convirtió en el gran regalo de Dios para la arquidiócesis contra el arreglo que había logrado el gobiemo con las autoridades eclesiásticas. A Monseffor Romero no se lo eligió para que fuera a ser lo que llegó a ser; se lo eligió casi para lo contrario. Pero el Espiritu Santo se apoderó de él y rompió todos los esquemas y perspectivas humanas, incluidos sus propios esquemas y perspectivas. Se convirtio en el gran regalo de Dios porque él mismo quedó totalmente convertido. No ocurrió todo de un golpe, aunque sl fue súbito el cambio inicial. El asesinato del padre Grande, el primero de los sacerdotes mártires que le locó enterrar, sacudió su conciencia. Se le rompieron los velos que le ocullaban la vendad y la nueva verdad empezó a apoderarse de todo su ser. No fue inicialmente un cambio subjctivo, sino una transformación objetiva. Se le descubrió algo que antes no había visto a pesar de su buena voluntad y de su pureza de intención, a pesar de sus horas de oración, y de su ortodoxia repetida, de su fidelidad al magisterio y a la jerarquía vaticana La luz se apoderó de el y esto le transformo. No es que el se transformase y así se le mostrase algo que antes no veía; más bien vio algo nuevo, algo objetivamente nuevo y esto lo transformó. Esto nuevo fue, en un primer momento, la verdad deslumbrante de un sacerdote que se había dedicado a evangelizar a los pobres, que en esa evangelización había llevado a los pobres a historizar la salvación, a dar came histórica a la palabra eternamente nueva de Dios. Por esto fue asesinado por quienes se sentían interpelados por esa palabra evangélica y por ese pueblo que lo habfa hecho came propia y hasta cierto punto proyecto político. Otros obispos y otros cristianos vieron en el martirio del padre Grande un suceso político e incluso dieron de él interpretaciones enceguecidas e increfbles. Monsefior Romero, no. Sus ojos limpios vieron la verdad. Y entonces se le reveló lo que significaba ser apostol en El Salvador de hoy; significaba ser profeta y ser márir. Y entonces comenzó la carrera de profela y de mártir, no porque él la hubiese elegido, sino porque Dios lo llenó con las voces históricas del sufrimiento de su pueblo elegido y con la voz de la sangre del primer justo que morfa martirialmente en El Salvador actual, para que todos tuvieran más vida y para que la Iglesia entera recuperara su pulso profético rebajado.

\section{La concreción histórica de su conversión}

Tras esta conversión inicial, que no es sino el comienzo de algo que pudo 
terminar ahi, Monseñor Romero entra en una nueva etapa, entra en una conversión profunda de su misión y es esta misión, la fidelidad a esta misión, lo que acaba transformando su vida y lo que lo convierte en factor fundarnental de la hiswria de la salvación en El Salvador. Es la misión, el sentido nuevo de su misión, lo que lo santifica más y más.

No acomoda la misión a lo que él había sido sino que acomoda toda su vida a la nueva misión.

Hasta entonces se había preocupado "también" de los pobres y oprimidos; desde ahora ellos van a convertirse en el centro orientador de su pastoral. La opción preferencial por el pueblo oprimido, hecha no en virtud de consideraciones teóricas, sino en virtud de su fidelidd al evangelio y en razón de que empieza a ver en ese pueblo oprimido al Jesús historizado que lo interpela y le exige, es lo que lo salva y lo que lo pone en condición de salvar. Cuando el pueblo apenas representaba algo para él, el apenas representaba nada para el pueblo, decíamos antes. Ahora afiadimos que cuando el pueblo apenas representaba algo para él, su anuncio del evangelio apenas tenía fuerza alguna, apenas era creßble. No era fuerza alguna, ni fuerza evangélica de salvación, ni fuerza histórica de liberación.

Comprende de una vez por todas que la misión de la Iglesia es el anuncio y la realización del reino de Dios, pero comprende al mismo tiempo que el anuncio y la realización del reino de Dios pasan ineludiblemente por el anuncio de la buena nueva a los pobres y de la liberación a los oprimidos. Pero lodo ello para que éstos ocupen su lugar propio en la Iglesia -la Iglesia de los pobresy para que ocupen su lugar propio en la tarea de la realización histórica del pueblo. Quiso y buscó que su palabra de salvación fuese operativa, y, para ello, que fuese asumida gozosamente, esperanzadamente por los destinatarios primeros y principales de esa palabra de salvación. Y llevó esta convicción hasta sus últimas consecuencias cuando vio, en el pueblo sin voz, a la voz misma de Dios, en el pueblo crucificado, al Dios Salvador, en las luchas de liberación, el camino para la llegada de la nueva tierra y del nuevo cielo.

El evangelio siempre se lee desde un lugar, siempre se lee situadamente; la fe se vive también situadamente. Esa lectura y esa vitalizaciớn nunca serán ni siquiera suficientemente adecuadas, si ese lugar y esa situación no son de modo preferencial el mundo de los oprimidos. Y en esto consistió la conversión apostólica de Monsefior Romero. Cambió de lugar, cambió de situación y lo que era una palabra opaca, amorfa e ineficaz se convirtió en un torrente de vida al que el pueblo se acercaba para apagar su sed. El pueblo sin voz hizo que su voz, la del obispo y la de la Iglesia, retumbase no sólo en el pás, sino internacionalmente; la crucifixión y la muerte de todo un pueblo se convertian en vida y en resurreción a través de Monsefior Romero; las luchas por la liberación encontraban a través de él un sentido transcendente que servia de aliento y de 
crítica a las dimensiones inmanentes de la tarea política.

Y por hacerlo así, corrió la misma sucrte que su pueblo. Vivió la calumnia, la difamación, la persecución. Se lo acusó de hacer políica en vez de hacer Iglesia; se lo acusó de fomentar la lucha de clases en vez de anunciar el amor; se lo acusó de predicar la violencia en vez de difundir el amor. Se lo acusó, como a Jesús, de agitar al pueblo y de prohibir pagar el tributo al César. Los sabios y prudentes de esle mundo, eclesiásticos, civiles y militares, los ricos y poderosos de este mundo así lo sentían y así lo decían. Pero el pucblo de Dios, los que tienen hambre y sed de justicia, los limpios de corazón, los pobres con espíritu, sabian que todo eso era falso, sabían y sentian que la palabra de Monseffor Romero era puro evangelio. Nunca habían sentido a Dios tan cerca, al Espiritu tan aparente, al cristianismo tan verdadero, tan lleno de sentido, tan lleno de gracia y de verdad. Por eso murio, por eso fue asesinado y por eso es un mártir. Por eso vive tan hondo en el corazón de su pueblo. Y si un dia el pueblo toma realmente el poder e inicia una dolorosa marcha en busca de la liberación total, la Iglesia no será tenida por extranta ya que para cse pueblo la Iglesia seguirá siendo la Iglesia de Monseñor Romero y Monseñor Romero nunca podrá ser extraño a un pueblo que lo amó, que confió en él, que esperaba de él palabras de vida eterna.

\section{La salvación del proceso histórico}

Monseñor Romero nunca se cansó de repetir que los procesos políticos, por muy puros e idealistas que sean, no bastan para traer a los hombres la liberación integral. Entendía perfectamente aquel dicho de San Agustín que para ser hombre hay que ser "más" que hombre. Para él, la historia que sólo fuese humana, que solo pretendiera ser humana, pronto dejaría de serlo. Ni el hombre ni la historia se bastan a si mismos.

Por eso no dejaba de llamar a la transcendencia. En casi todas sus homilías salía este terna: la palabra de Dios, la acción de Dios rompiendo los límites de lo humano. Una transcendencia que nunca se presentaba como abandono de lo humano, como huída del hombre, sino como su superación y perfeccionamiento. Un más allá que no abandonaba el más acá, sino que lo abría y lo impulsaba hacia adelante.

Por eso buscaba una auléntica salvación del proceso histórico y la salvación de un proceso, que como proceso histórico liene sus propias leyes autónomas. Dicho en ouros términos, no deshistorizaba el proceso real con sus concretas condiciones intramundanas. Lo que hacía era quitarle su carga de pecado y abrirle a sus mejores posibilidades transcendentes. Y esto desde la perspectiva cristiana tanto en la delimitación y condena de lo que es pecado, como en la delimitación de lo que son las mejores posibilidades transcendentes.

De ahf que se ensafiara —aunque en su corazón no había saña alguna- 
contra la injusticia. Sobre todo contra la injusticia de los poderosos contra las mayorias oprimidas. De ahí que peleara contra cualquier absolutización de lo fúnil y humano, sobre todo contra la absolutización del poder y de la riqueza, pero también de las propias ideas - dogmatismo- y de la propia organización - sectarismo. De ahí que hablase en favor del pueblo para que él mismo construyese críticamente un mundo nuevo en el cual los valores predominantes fuesen la justicia, el amor, la solidaridad, la libertad. De ahí que una y otra vez pusiera sus ojos en Jesús como principio de la fe y de la transcendencia cristianas.

Y el pueblo se abría a la transcendencia cristiana La palabra, la vida, el ejemplo de Monsefior Romero hacían creíble el mensaje cristiano a cada vez mayor parte del pueblo salvadorefio, porque cada vez lo abría a una esperanza siempre más grande y más pura. El pueblo recibía de Monseftor Romero fuerza nueva para esperar, para luchar esperanzadamente, para ofrendar sus vidas llenando de sentido su sacrificio heroico. La Iglesia, en contrapartida, recibía credibilidad y fuerza de ese pueblo que cada vez se fraba más de ella en una nueva ctapa ya no ingenua, sino crítica.

Por eso puede y debe hablarse de que con él se empezó a realizar, de un modo sorpendentemente eficaz, la salvación del proceso histórico que se está cumpliendo en El Salvador.

Impulsó esc proceso en su concreta realidad histórica porque veía en él más luz que tinieblas, más vida que violencia, y tomó partido por ese proceso en cuanto favorecía al pueblo oprimido. Pero no se identificó con él sin más porque el evangelio necesita encarnación "en", pero no identificación "con" un determinado proceso histórico. Esa encarnación evangélica le bastó para combatir proyectos políticos bien reales sin la fácil escapatoria de los principios, como si el profcta cristiano no tuviera que anunciar sino generalidades abstractas. Y esa encarnación le ganó el amor del pueblo primido y el odio del opresor. Le ganó la persecución, la misma persecución que sufría su pueblo. Así murió y por eso lo mataron. Por eso igualmente se convirtió en un ejemplo excepcional de cómo la fuerza del evangelio puede convertirse en fuerza hisıórica de transformación. Por eso sigue viviendo tras su muerte, y esto no sólo porque son muchos los que lo recuerdan, no sólo porque son muchos los que vieron quitada la venda que les impedia reconocer la verdad del evangelio, sino sobre todo porque son muchos los que están dispuestos a seguir sus pasos, sabiendo que Monseñor Romero, en los últimos tres affos de su vida pública, fue un seguidor ejemplar de Jesús de Nazaret. 